\section{IL GRAFFIO Mi importa di te}

Sono stato, l'altro giorno, alla cerimonia delle Specializzazioni in Pediatria.

$E$, oltre che dalla presentazione delle tesi, sono stato ancora più preso dal racconto libero che ogni specializzando ha fatto della sua esperienza formativa. Un intreccio di bravura, entusiasmo, riconoscenza, professionalità comunicativa. E anche di gioia: nel poter mostrare a tutti (parenti, amici, colleghi, docenti) che si, era proprio vero, la scuola li aveva fatti maturare, aveva accresciuto sicurezza e autostima, aveva rinsaldato la convinzione e l'entusiasmo per la scelta fatta. Belle persone, ho pensato, con lo sguardo paterno e un po' distaccato del pensionato. Ho avuto, mi sono detto, per tanti anni, una grande fortuna, un impagabile previlegio, nel rinnovare l'incontro con tante diverse bravure. Nell'aver avuto, forse, anche una piccola parte nell'appassionarli al lavoro che avevano scelto e nell'aiutarli a trovare in questo il massimo del divertimento e della gratificazione possibile. In qualche modo, peraltro, anche loro hanno fatto capire di sentirsi fortunati: soprattut- to, mi è sembrato di capire, per la certezza, avuta dal primo momento, che quella dove erano giunti per imparare la Pediatria era la loro casa e che, per tutti, in questa casa loro erano molto importanti. Se alziamo un po' lo sguardo su tutta la società e riflettiamo sulle nostre responsabilità negli intoppi generazionali che la caratterizzano, ecco, è forse proprio questo che manca, che non sappiamo dare (o non ci importa di dare) ai giovani: la certezza che di loro ci importa. La certezza che per noi rappresentano un investimento irrinunciabile: che investire su di loro è per noi motivo di realizzazione, in qualche modo di gioia e divertimento. Del resto, si dice, il più bravo degli insegnanti è quello che si diverte a insegnare e che di questo divertimento, di questo desiderio, dà certezza a chi deve imparare. "Di te, bambino, di te adolescente, di te giovane che ti aspetti qualcosa da me, ebbene si: abbi la certezza che mi importa. E questa importanza che ti do è la mia realizzazione, il mio divertimento". È perché è proprio cosi che abbiamo fatto $i$ pediatri (?).

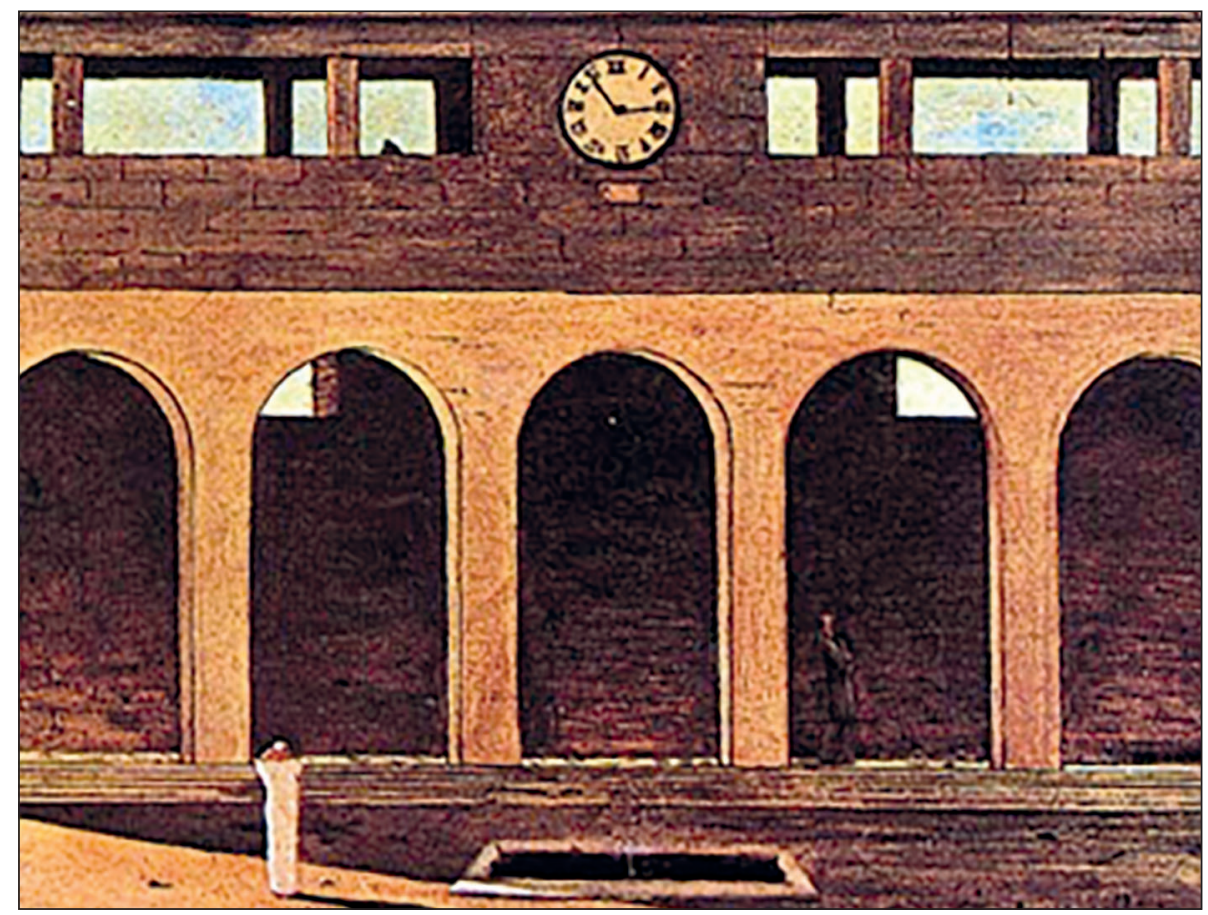

Giorgio De Chirico. L'enigma dell'ora (1911). 